\title{
The Relationship between Positive Emotion and Resilience Among Undergraduate Students
}

\section{Anusyaasyini Magalinggam \& Fatanah Ramlee}

To Link this Article: http://dx.doi.org/10.6007/IJARBSS/v11-i6/10078

DOI:10.6007/IJARBSS/v11-i6/10078

Received: 09 April 2021, Revised: 13 May 2021, Accepted: 29 May 2021

Published Online: 08 June 2021

In-Text Citation: (Magalinggam \& Ramlee, 2021)

To Cite this Article: Magalinggam, A., \& Ramlee, F. (2021). The Relationship between Positive Emotion and Resilience Among Undergraduate Students. International Journal of Academic Research in Business and Social Sciences, 11(6), 27-35.

\section{Copyright: @ 2021 The Author(s)}

Published by Human Resource Management Academic Research Society (www.hrmars.com)

This article is published under the Creative Commons Attribution (CC BY 4.0) license. Anyone may reproduce, distribute, translate and create derivative works of this article (for both commercial and non-commercial purposes), subject to full attribution to the original publication and authors. The full terms of this license may be seen at: http://creativecommons.org/licences/by/4.0/legalcode

Vol. 11, No. 6, 2021, Pg. 27 - 35

Full Terms \& Conditions of access and use can be found at http://hrmars.com/index.php/pages/detail/publication-ethics 


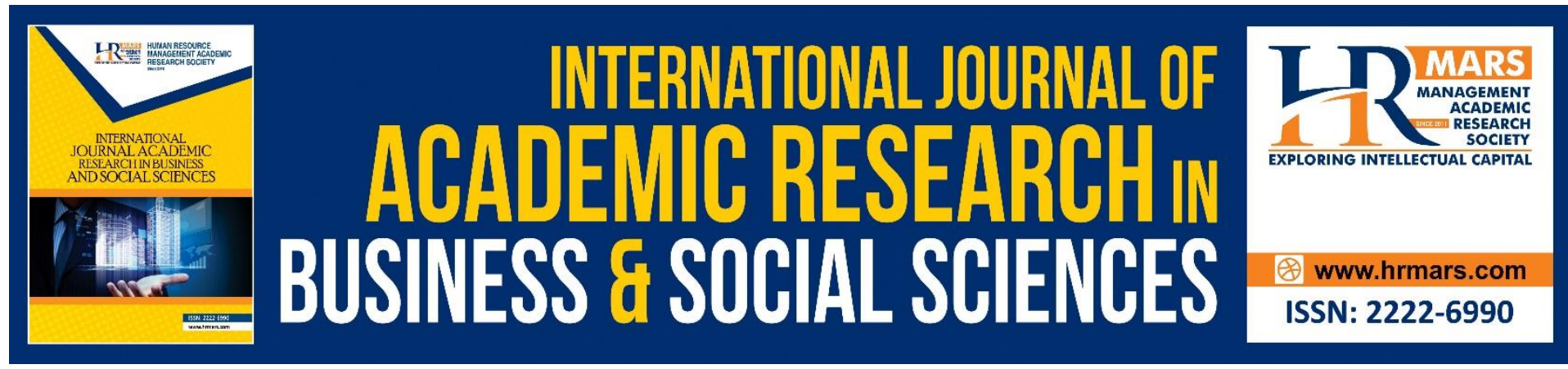

\title{
The Relationship between Positive Emotion and Resilience Among Undergraduate Students
}

\author{
Anusyaasyini Magalinggam \& Fatanah Ramlee \\ Sultan Idris Education University Malaysia
}

\begin{abstract}
Although the numbers of youths entering universities in Malaysia are increasing rapidly, several studies have shown that some students are suffering from poor mental health which could lead them to have experience positive emotions and more negative emotions. This study aimed to investigate the relationship between positive emotion and resilience among UPSI undergraduate students and to examine the difference between male students and female students in positive emotion and resilience. Cross-sectional survey design was applied to gather the data of 140 participants using both paper and pencil method and online survey method. A set of questionnaire comprising demographic information, Dispositional Positive Emotions Scales (DPES) to measure positive emotions and Brief Resilience Scale (BRS) to measure resilience was given. Using Pearson's product-moment correlation analysis, it was found that there was a significant relationship between positive emotion and resilience, $r=$ 0.4. Thus, null hypothesis is rejected. The correlation coefficient obtained showed that there is positive correlation between positive emotion and resilience among UPSI students in which students with more positive emotion are more likely to have higher level of resilience. Based on the t-test analysis, the difference was not significant between male students and female students for both positive emotions and resilience. In conclusion, more positive psychology programs can be conducted to educate the students about good mental health and well-being which will eventually increase their psychological resilience in facing challenges in their university lives.
\end{abstract}

Keywords: Positive Emotions, Resilience, DPES, BRS, Undergraduate Students.

\section{Introduction}

Undergraduate students often experience challenges as the university life is a transition period from late teens to young adulthood in which they need to learn, adjust, adapt or cope with changes in their everyday life (Arnett, 2000; Trigueros et al., 2020). Positive emotions are important elements for individuals because positive emotion could help people to transform into more creative, resilient, knowledgeable, and healthy individuals engage in proactive social relationships with others (Fredrickson, 2004; Diener et al., 2020). Fredrickson (2001) defined emotion as "multi module reaction tendencies that develop over reasonably in less time" that are grouped in emotional families. Individuals could experience both emotions since they are split up into positive and negative emotions. Positive emotions 
are good feelings that show human flourishing and by using positive emotions could help individuals to bounce back from negative experience (Fredrickson, 2012). Among ten most common positive emotions are joy, gratefulness, serenity, interest, hope, satisfaction, amusement, inspiration, awe, and affection (Fredrickson, 2009).

Previous studies have shown that positive emotions have been associated with various beneficial outcomes such as higher level of work satisfaction (Losada \& Heaphy, 2004) higher life satisfaction (Cohn et al, 2009), and academic motivation (Low, King, \& Caleon, 2016)). A review of positive emotions by Lyubomirsky et al. (2005) mentioned that positive emotions not only bring satisfaction and success at work but also good relationships with others and better physical health maintenance.

Resilience has played an important role for young adults and adolescents in maintaining good health and wellbeing. Walker et al (2017) suggested that the psychological strength to face hurdles in life an individual possesses is the root of the resilience trait. Ahmad, Khairani, and Aman (2018) conducted a cross-sectional study among university students from the School of Health Sciences programme $(n=94)$ and School of Electrical Engineering programme $(n=254)$. The findings showed that Health Sciences students had higher level of resilience compared to electrical engineering students. Possibly this is due to the challenging clinical learning curriculum that requires students to prepare themselves to become competent and building up resilient throughout their studies.

Arewasikporn, Sturgeon and Zautra (2019) investigated the effect of shared enjoyment and positive emotions on resilience thinking. Based on the data collected on 191 middle-aged adults (mean age $=53.51$, the researchers concluded that individuals experiencing positive events and had a positive effect tend to have a resilient mindset and greater well-being. Meanwhile Seaton, Bottorff, Jones-Bricker, and Lamont (2018) found that emotional outlook and positive emotion has a positive correlation with ego-resilience in which ego-resilience act as the mediator for these factors and physical activities among men.

Although the numbers of youths entering universities are increasing rapidly, past studies showed that the students do not have enough confidence in higher education because they are not able to find what they are looking for in the university, lacking education that they obtained throughout their university life to obtain a job and other social and psychological problems (Wong \& Chiu, 2018). Although they are able to achieve their academic success, Malaysian students are suffering from poor mental health (Mey \& Yin, 2015; Ministry of Health, 2016). Several researchers have found out that mental health among adolescents and university students is getting worse day by day in which the level of distress, anxiety, and depression are arising among them (Twenge, Roger, Joiner \& Martin, 2018). A high level of resilience has been considered as a trait that could reduce mental health problems (Shi et al., 2016). Therefore, the aim of the present study was to examine the relationship between positive emotions and resilience among undergraduate students of Sultan Idris Education University (UPSI) and to examine gender differences in positive emotions and resilience.

\section{Method}

\section{Research Design}

A cross-sectional survey design was used in this study in which the participants were given a set of questionnaires to be completed either through online platform or paper-andpencil. The data obtained was used to examine the participant's level of positive emotion and resilience as well as to investigate the association between positive emotion and resilience. 


\section{Participants}

The population for this study was undergraduate students of UPSI who are enrolling in diploma and bachelor degree programme age ranging from 18 to 26 years old. The study was conducted in Universiti Pendidikan Sultan Idris (UPSI). The participants were recruited using convenience sampling. A total of 140 students enrolling undergraduate programs and diplomas took part in this study. G*power software was used to determine the sample size required for this study. According to the $\mathrm{G}^{*}$ power calculation, 105 participants were required for this study. 21 students or more were required in order to have a confidence level of $90 \%$. This would ensure the real value is within $\pm 10 \%$ of the measured value. Thus, a total of 140 participants were recruited to be conservative and cover the survey dropout rate.

\section{Instruments}

A set of questionnaire comprising demographic questions and two scales were used in this study. Demographic questions were asked to identify some basic characteristics of the participants. Dispositional Positive Emotion Scale (DPES; Shiota, Keltner \& John, 2006) was used to measure the positive emotions and Brief Resilience Scale (BRS; Smith et al., 2008) was used to measure the dependent variable, resilience.

\section{Back Translation}

The questionnaires were using Malay language. According to the Brislin model for instrument translation, an individual who has good proficiency in two languages will translate the instruments from its original language to the targeted language (Brislin, 1970). In this research, the instruments DPES and BRS that were originally in the English language translated into the Malay language. Then, another individual who was bilingual translated the instruments back into its original language, English, and this process is known as backtranslation. It was then followed by the comparing both original and back-translated version. Any discrepancy was resolved through team discussion. The Malay version questionnaire was tested in a pilot study with 10 participants who had similar characteristics with the target participants. This pilot study helped the researchers to identify the ambiguities, readability of the questionnaire and time completion.

\section{Procedure}

Participants recruitment advertisement were circulated around campus (e..g., library, café) and through online (e.g., WhatsApp, Telegram). Potential participants who responded to the advertisement were then invited to take part in the study and completed the informed consent form. Participation in this study was voluntary and they can withdraw from the research at any time without giving reasons. Participants took approximately 10-15 minutes to complete the questionnaire. This study has been reviewed and approved by the evaluation committees at the Department of Psychology and Counselling, UPSI.

\section{Analysis}

Data analysis were completed using Statistical Packages Social Sciences (SPSS) Statistics Version 23. Means, standard deviations, frequency and percentage were presented for descriptive statistics, while Pearson correlation was run to test relationship between positive emotions and resilience. Besides, t-test was run to examine gender differences. 


\section{Findings}

\section{Participant characteristics}

A total of 140 undergraduate students took part in this study. $71.4 \%$ of the students were degree students meanwhile $28.6 \%$ of them are diploma students. Out of 140 participants, 66 of them were males and 74 females. The age of participants ranged from 18 to 26 years old $(M=21.41 ;$ S.D. $=1.61)$ and the majority of them were 22 years old $(n=50)$.

Participants from various ethnics took part in this study. Most of the participants were Malays ( $n=60)$, followed by Indians ( $n=39)$, Chinese $(n=26)$ and other minor ethnics $(n=15)$. The majority of the participants were Semester 7 students $(n=43)$ while the least from Semester 1, in which only two students from the first semester participated in this study. Table 1 present the demographic information about the participants.

Table 1. Participant characteristics

\begin{tabular}{|c|l|l|l|l|}
\hline & $\begin{array}{l}\text { Frequency } \\
(\mathbf{n = 1 4 0 )}\end{array}$ & Percentage (\%) & $\boldsymbol{M}$ & S.D. \\
\hline & & & & \\
\hline Age (years) & - & - & 21.41 & 1.61 \\
\hline Gender & & & & \\
\hline Male & 66 & 47.1 & - & - \\
\hline Female & 74 & 52.9 & - & - \\
\hline Ethnicity & & & & \\
\hline Malay & 60 & 42.9 & - & - \\
\hline Chinese & 26 & 18.6 & - & - \\
\hline Indian & 39 & 27.9 & - & - \\
\hline Others & 15 & 10.7 & - & - \\
\hline Program & & & & \\
\hline Diploma & 40 & 286 & & \\
\hline Degree & 100 & 71.4 & & \\
\hline
\end{tabular}

A Pearson's product-moment correlation was run to examine the relationship between positive emotion and resilience among undergraduate students. The study hypothesized that there is a significant relationship between positive emotion and resilience among undergraduate students of UPSI.

Table 2 shows the significant association between positive emotion and resilience, $r=$ $.43, p$ (two-tailed) $=.01$ indicating there is positive correlation between positive emotion ( $\mathrm{M}$ $=4.74, S D=0.95)$ and $B R S$ resilience $(M=3.29, S D=.61)$ that is positive emotion increases as resilience level increases. Pearson correlation coefficient, $r$ of .43 indicates that there is a moderate correlation between positive emotions and resilience among undergraduate students in UPSI. Thus, the null hypothesis is rejected and the alternative hypothesis is accepted. 
Table 2. Pearson correlation coefficients between positive emotion and resilience

\begin{tabular}{|l|l|l|}
\hline & Positive emotion & Resilience \\
\hline Positive emotion & 1 & $.43^{* *}$ \\
\hline & & .00 \\
\hline Resilience & & 1 \\
\hline
\end{tabular}

Independent t-test was run to investigate the difference in the level of positive emotion and resilience between male and female participants. Based on the t-test analysis, it is found that there is no statistically significant difference in the mean level of positive emotion between male and female undergraduate students of UPSI. On average, male undergraduate students experienced slightly higher level of positive emotions ( $M=4.75, S D$ $=1.09)$ than the female undergraduate students $(M=4.72, S D=.82)$. This differences was not significant $\mathrm{t}(138)=.17, \mathrm{p}=0.87$. The results also revealed that there is no statistically significant difference in the mean level of resilience between male and female participants $t$ $(138)=-.52, p=.61$. Although on average male undergraduate students showed a higher level of resilience $(M=3.26, S D=.67)$ compare to female undergraduate $(M=3.32, S D=.57)$, the different is not significant.

\section{Discussion}

As hypothesized, the presence of a significant relationship between positive emotions and resilience among the undergraduate students in UPSI was expected. The study demonstrates a positive correlation between positive emotion and resilience among undergraduate students in which those students who have more positive emotions are more likely to have a higher level of resilience. In line with the hypothesis, previous studies have suggested that being emotionally positive could be an important factor in order to increase the level of resilience and to be resilient in life (Sophie, 2016).

The findings of the current study found substantial support in the explanation by Denovan and Macaskill (2017) who stated that undergraduate students who are highly resilient apply leisure coping to increase positive emotions in them that eventually improve their overall well-being. Leisure coping and positive emotions act as mediators between resilience and well-being among undergraduate students who experience a high level of stress (Denovan \& Macaskill, 2017). Additional evidence also showed that undergraduate students from the University of Michigan with higher trait resilience had a high level of positive emotions specifically on eagerness, excitement, and happiness (Tugade \& Fredrickson, 2004).

Based on the hypothesis, it was expected that the male students and female students have a different level of positive emotion and resilience. However, after running an independent t-test using the data obtained, the alternative hypotheses were rejected and the null hypotheses were accepted. It was concluded that there is no statistical difference between genders in the level of positive emotions and resilience. The results of this study support the claims by Zuckerman, Li, and Diener (2017) who concluded that men and women did not statistically differ in terms of positive emotions. However, the finding of this study is contradicted to the result of several past studies. Women are more prescribed to feel as to how society wants them to feel than men. Women tend to express positive emotions nonverbally such as smiling and laughing compared to the opposite genders (LaFrance, Hecht, \& 
Paluck, 2003). It was concluded that women are more prescribed to the expression of positive emotion than men.

Current result which stated that there is no statistical difference between genders in the level of resilience is contradicted with the finding of a study conducted by Sarwar, Inamullah, Khan, and Anwar (2010) in Pakistan which stated that female students had a lower level of resilience than the male students. The differences in the findings can be because of the gender equality differences based on the countries. For example, Malaysia follows and emphasizes gender equalities to explore and achieve their goals, thus have more good values in themselves such as resilience and self-discovery than the female students in countries that are more male-dominated.

There were several limitations in this study. The findings of this study are not appropriate to be generalized to the whole population of UPSI students because the participants of this study were only local students but the population of this study includes both local and foreign students, thus this study only represents the local UPSI students. Thus, future studies should include both local and foreign students and use a larger sample. This study builds on existing evidence to past studies that claimed positive emotions and resilience are correlated and men and women do not differ in the level of positive emotions and resilience. Considering the findings of this study, they are not only beneficial for the students, but also to the educational practices as well. More positive psychology programs can be conducted in order to maintain the students' good mental health which will eventually increase their psychological resilience in facing challenges in their university lives. Other interventions and learning techniques can be implemented in the university to promote positive emotions among the undergraduate students and also the staff of UPSI.

\section{Conclusion}

The results of the current study suggest that there is a significant relationship between positive emotions and resilience among undergraduate students but there is no gender differences in positive emotions and resilience.

\section{Acknowledgement}

The present study is a final year project of Anusyaasyini Magalinggam in partial fullfilment of Bachelor Degree of Psychology (Honours).

\section{Corresponding Author}

Fatanah Ramlee

Department of Psychology and Counselling, Faculty of Human Development, Sultan Idris Education University, 35900 Perak MALAYSIA

Email: fatanah@fpm.upsi.edu.my

\section{References}

Ahmad, N. S., Khairani, A. Z., \& Che Aman, R. (2018). Assessing resiliency among Malaysian university undergraduates. Advances in Social Science, Education and Humanities Research, 3, 82-85

Arewasikporn, A., Sturgeon, J. A., \& Zautra, A. J. (2018). Sharing positive experiences boosts resilient thinking: Everyday benefits of social connection and positive emotion in a 
community sample. American Journal of Community Psychology, 63(1-2), 110-121. doi: 10.1002/ajcp.12279

Brislin, R. W. (1970). Back-translation for cross-cultural research. Journal of Cross-Cultural Psychology, 1(3), 185-216. https://doi.org/10.1177/135910457000100301

Cohn, M. A., Fredrickson, B. L., Brown, S. L., Mikels, J. A., \& Conway, A. M. (2009). Happiness unpacked: Positive emotions increase life satisfaction by building resilience. Emotion, 9(3), 361-368. doi:10.1037/a0015952

Denovan, A., \& Macaskill, A. (2017). Stress, resilience and leisure coping among university students: applying the broaden-and-build theory. Leisure Studies, 36(6), 852-865.

Fredrickson, B. L. (2001). The role of positive emotions in positive psychology: The broadenand-build theory of positive emotions. American Psychologist, 56(3), 218-226. doi:10.1037/0003-066X.56.3.218

Fredrickson, B. L. (2004). The broaden-and-build theory of positive emotions. Philosophical transactions of the royal society of London, Series B: Biological Sciences, 359(1449), 1367-1377. doi:10.1098/rstb.2004.1512

Fredrickson, B. L. (2009). Positivity: Groundbreaking research reveals how to embrace the hidden strength of positive emotions, overcome negativity, and thrive. New York, NY: Crown.

Harms, W., \& DePencier, I. (1996). Dewey creates a new kind of school. Diperoleh semula daripada http://www.ucls.uchicago.edu/about-lab/history/index.aspx

LaFrance, M., Hecht, M. A., \& Paluck, E. L. (2003). The contingent smile: A meta-analysis of sex differences in smiling. Psychological Bulletin, 129(2), 305-334

Losada, M., \& Heaphy, E. (2004). The role of positivity and connectivity in the performance of business teams: A nonlinear dynamic model. American Behavioral Scientist, 47(6), 740-765. doi: 10.1177/0002764203260208

Low, M., King, R. B., Caleon, I. S. (2016) Positive Emotions Predict Students' Well-Being and Academic Motivation: The Broaden-and-Build Approach. In: King R., Bernardo A. (eds) The Psychology of Asian Learners. Springer, Singapore. https://doi.org/10.1007/978981-287-576-1_30

Lyubomirsky, S., Sheldon, K. M., \& Schkade, D. (2005). Pursuing happiness: The architecture of sustainable change. Review of general psychology, 9(2), 111-131.

Meirink, J. A., Imants, J., Meijer, P. C., \& Verloop, N. (2010). Teacher learning and collaboration in innovative teams. Cambridge Journal of Education, 40(2), 161-181.

Mey, C., \& Yin, C. J. (2015). Mental health and wellbeing of the undergraduate students in a research university: A Malaysian experience. Social Indicators Research, 122(2), 539551.

Ministry of Health. (2016). Press statement by Minister of Health Malaysia. Retrieved from http://www.moh.gov.my/english.php/database_stores/store_view_page/22/451.

Sarwar, M., Inamullah, H., Khan, N., \& Anwar, N. (2010). Resilience And Academic Achievement Of Male And Female Secondary Level Students In Pakistan. Journal of College Teaching \& Learning (TLC), 7(8). https://doi.org/10.19030/tlc.v7i8.140

Seaton, C. L., Beaumont, S. L. (2015). Pursuing the good life: A short-term follow-up study of the role of positive/negative emotions and ego-resilience in personal goal striving and eudaimonic well-being. Motiv Emot, 39, 813-826

Shi, J., Chen, Z., Yin, F., Zhao, J., Zhao, X., \& Yao, Y. (2016). Resilience as moderator of the relationship between left-behind experience and mental health of Chinese adolescents. International Journal of Social Psychiatry. 62(4), 386-393. 
Shiota, M. N., Keltner, D., \& John, O. P. (2006). Positive emotion dispositions differentially associated with Big Five personality and attachment style. The Journal of Positive Psychology, 1(2), 61-71.

Smith, B. W., Dalen, J., Wiggins, K., Tooley, E., Christopher, P., \& Bernard, J. (2008). The brief resilience scale: assessing the ability to bounce back. International journal of behavioral medicine, 15(3), 194-200.

Sophie, A. K. (2016). Emotion regulation and resilience: Overlooked connections. Industrial and Organizational Psychology, 9, 411-415

Tugade, M. M., \& Fredrickson, B. L. (2004). Resilient individuals use positive emotions to bounce back from negative emotional experiences. Journal of personality and social psychology, 86(2), 320.

Twenge, J., Roger, M., Joiner, T., \& Martin, G. (2018). Increases in depressive symptoms, suicide-related outcomes, and suicide rates among U.S. adolescents after 2010 and links to increased new media screen time. Clinical Psychological Science. 6. doi: $10.1177 / 2167702617723376$

Walker, F. R., Pfingst, K., Carnevali, L., Sgoifo, A., \& Nalivaiko E. (2017). In the search for integrative biomarker of resilience to psychological stress. Neurosci Biobehav

Zuckerman, M., Li, C., \& Diener, E. F. (2017). Societal conditions and the gender difference in well-being: Testing a three-stage model. Personality and Social Psychology Bulletin, 43(3), 329 Goh, P. S. C., \& Wong, K. T. (2013). Beginning teachers' conceptions of competency: Implications to educational policy and teacher education in Malaysia. Educational Research for Policy and Practice. Advance online publication. Doi: 10.1007/s10671-013-9147-3 